\title{
CORRESPONDENCE
}

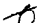

Rationing of Medical Care

H. W. Ashworth, F.R.C.G.P. . . . . . . . 569

Health Education in the Reorganized

N.H.S.

E. A. Smith, F.R.C.P.GLAS., and L. Baric,

PH.D.; L. Bowcock, M.B.................5569

Inquiry among Rheumatism Unit Out-

patients
F. D. Hart, F.R.C.P., and others. . . . . . 570

Hyperglucagonaemia in the Surgical Patient

A. E. B. Giddings, F.R.C.S., and others . . . . 570

Glucagon and Pseudogout

A. J. Richards, M.R.C.P... . . . . . . . . . 570

Genitourinary Medicine

R. A. Mogg, F.R.C.s.............570

Television Programme on Induction of

Labour

L. E. S. Carrie, F.F.A. R.C.S. . . . . . . . . 571

Leeds Infirmary Blues

J. G. Goligher, F.R.C.S., and J. S. Scott, F.R.C.o.G.; D. J. Rodgers, M.B..........571

Fibrinolysis and Venous Thrombosis

I. C. Gordon-Smith, F.R.c.s., and J. A.

Hickman, M.R.C.P.............. A
Prisoners' and Their Health

P. J. Day, M.B., and T. Bell; J. R. W. Christie

Brown, M.R.C.PSYCH.................

Misleading Drug Advertising

L. F. Prescott, F.R.C.P.ED... .

Women Doctors in the N.H.S.

Shrubshall, M.R.C.P.PSYCH. ; Nancy K.

Alpha-fetoprotein in Amoebic Colitis and Liver Abscess

E. P. Gétaz, M.R.C.P. . . . . . . . . 573

Levodopa and Dopadecarboxylase in

\section{Treatment of Postural Hypotension}

F. Boismare and J. Boquet............573

Men, Women, and Obesity

D. G. Altman, B.SC., and L. M. Irwig, M.B. . 573 SI Units

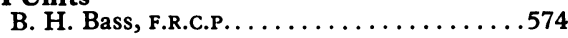

Tafracher

D. S. Thompson, M.R.C.PATH. . . . . . . 574

Comparison between Free Thyroxine

Index and Effective Thyroxine Ratio

M. L. Wellby, F.R.C.P.A., and others... . . 574
Venous Gangrene in Multiple Myeloma A. N. Chatterji, M.R.C.P., and G. H. Apthorp

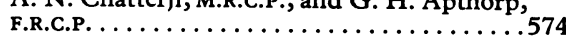

Ilness in the Clouds

J. C. Kelsey, F.R.C.Path... . . . . . . . 575

New Causes of Malignant Hyperpyrexia

F. R. Ellis, F.F.A. R.C.S., and others....... 575

Changing from High- to Low-dose Oral

Contraceptive
M. Briggs, D.SC., and Maxine Briggs, M.B. . 575

Methodology of Sickness Absence

Analysis

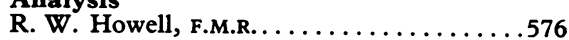

Consultant Contract

R. Moore, M.R.C.P.; G. St. J. Hallett, F.R.C.S. 576

Difficulties of Emigration

R. G. Huntsman, F.R.C.P. . . . . . . . . . 576

Sanctions by G.P.s

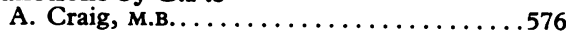

Subscription of Retired Members

A. D. Bateman, F.R.C.S............ 576
Correspondents are urged to write briefly so that readers may be offered as wide a selection of letters as possible. So many are now being received that the omission of some is inevitable. Letters should be signed persomally by all their authors.

\section{Rationing of Medical Care}

SIR,-In the Telfond Memorial Lecture delivered by Dr. Henry Yellowlees on 19 February to the Manohester Medical Society the Chief Medical Officer explained that in his view, and indeed in the view of the politicians, medical care must somehow be rationed in a situation of unlimited demand and limited resources. He was then asked, "Will the Department of Health and Social Security then explain to the public and to the profession exactly how this rationing is to be implemented?" He replied, "No, I think the profession must tell us how the rationing is to be effected."

This is another example of double talk. It is the politicians and the D.H.S.S. who continually tell the public that they are

entitled to have all their medical and medicosocial needs satisfied. In these circumstances it is no wonder that doctors try to implement this policy, for if they fail they are castigated in Parliament or at complaints tribunals or in the press. The politicians cannot expect the profession to implement rationing of medical care and then incur the odium which will ensue. It is up to the politicians and the D.H.S.S. in their managerial capacity to explain to the public the need for some limitation in the demands made and to spell out exactly what this will be.-I am, etc.

Darbishire House Health Centre,

H. W. ASHWORTH

University of Manchester,

Manchester

\section{Health Education in the Reorganized N.H.S.}

SIR,-Your leading article ( 1 February, p. 233) on health education in the reorganized N.H.S. does not carry its timely analysis of the problems far enough. The importance of behaviour as an aetiological agent and as a determinant of outcome in so many of the chronic diseases prevalent at the present time demands that health education should be an integral element in preventive, curative, and mitigative medicine at all levels from the clinical to the population scale. If this is to be achieved health education must be not only firmly established within the Health Service but established at an adequate professional level so that it may make its contribution to all stages in the processes of planning and implementing health policy.
Internationally the specialist in health education is commanding a status commensurate with that accorded to the members of the other health professions, and resolutions of the World Health Organization, stemming both from headquarters and from the regional offices, have called for the development of professional education within this field at an adequate postgraduate level. While diploma courses rooted largely within faculties of education may possibly provide for the needs of health education considered as a branch of general education they do not really meet the need for professional training of health education specialists for work within a health service context.

Programmes leading to health education qualifications at the master's degree level have been established-albeit precariouslyin one or two medical sohools in Britain, usually in association with departments of community medicine. The continued development of these programmes will depend crucially on the availability of appropriate financial support for candidates who pursue them. There would be much to be said for the development of in-service professional training programmes associated with master's degree courses along the lines of the training programmes already being established for specialists in community medicine. It would be desirable to reoognize the educational needs of the small body of people who have established their reputations in the field without formal training and whose contribution might be further enhanced by secondment for appropriate university-based studies. Our experience of having a number of such persons pursue our own M.Sc programme has been very rewarding indeed. -We are, etc.,

ALWYN SMITH LEO BARIC

Department of Community Medicine,

University of Manchester,

SIR,-Your leading article on health educa tion in the reorganized National Health Service (1 February, p. 233) highlights one facet of the larger problem of training in many areas to which the N.H.S. is now committed but for a variety of reasons is not making the progress it should.

Experience in my department indicates that co-operation between health department officers (and also training officers and tutors) and departments of medical photography and illustration can result in the production of effective publicity and training material at modest cost. The local flavour of this material increases its effectiveness and the 